Meta

Journal des traducteurs

Translators' Journal

\title{
Sobre didáctica de la traducción
}

\section{Rosario García López}

Volume 49, numéro 2, juin 2004

URI : https://id.erudit.org/iderudit/009368ar

DOI : https://doi.org/10.7202/009368ar

Aller au sommaire du numéro

\section{Éditeur(s)}

Les Presses de l'Université de Montréal

ISSN

0026-0452 (imprimé)

1492-1421 (numérique)

Découvrir la revue

Citer cette note

López, R. G. (2004). Sobre didáctica de la traducción. Meta, 49(2), 432-446. https://doi.org/10.7202/009368ar

\section{Résumé de l'article}

Le grand nombre d'écrits sur la théorie et la pratique de la traduction n'est pas comparable à celui consacré à la didactique d'une activité dont l'étude et l'apprentissage font depuis longtemps l'objet de recherches universitaires.

Les raisons de ce déséquilibre sont nombreuses et variées, l'absence d'unanimité entre les spécialistes dans ce domaine, sur la nature et l'objet de la traduction, étant peut-être l'une des plus importantes.

Puisqu'il nous faut former des étudiants à la pratique de cette discipline, une méthodologie cohérente et rigoureuse, conçue à partir d'une théorie claire qu'il soit possible d'appliquer à la traduction de tout type de texte, s'avère nécessaire.

Cette méthodologie atteindra son but si nous parvenons à montrer aux étudiants un point de départ, des objectifs et un parcours intermédiaire, suivant des considérations traductologiques dont le dénominateur commun est leur vocation de faciliter la communication entre la culture de départ et la culture d'arrivée.

Dans cet article nous présenterons notre modèle didactique, fruit de notre expérience dans l'enseignement universitaire, mais qui ne prétend pas être exclusif. Ce modèle se veut seulement un point de départ pour la réflexion et une aide pour des professeurs et des étudiants.
Ce document est protégé par la loi sur le droit d'auteur. L'utilisation des services d'Érudit (y compris la reproduction) est assujettie à sa politique d'utilisation que vous pouvez consulter en ligne.

https://apropos.erudit.org/fr/usagers/politique-dutilisation/ 
13) NA-Exp1p-EYL= NA obtained through an expansion 1 of a phrase with loss of communicative efficiency.

14) NA-Exp2-EYL = NA obtained through an expansion2 with loss of communicative efficiency.

\section{Deletions (D) (9 items)}

15) D-R1s-EYL/EFLS/EFLE = Deletion of a sentence due to a reduction1 of a whole predication with loss of communicative efficiency, effectiveness and emphasis with respect to the original text.

16) D1-R1c-EFLS/EFLE = Deletion1 due to a reduction 1 of a clause with loss of communicative effectiveness and/or emphasis with respect to the original text.

17) D1-R1p-EFLS/EFLE= Deletion1 due to a reduction 1 of a phrase with loss of communicative effectiveness and/or emphasis with respect to the original text.

18) D1-R2c-EFLS/EFLE = Deletion1 due to a reduction2 of a clause with loss of communicative effectiveness and/or emphasis with respect to the original text.

19) D1-R2p-EFLS/EFLE= Deletion 1 due to a reduction2 of a phrase with loss of communicative effectiveness and/or emphasis with respect to the original text.

20) D2-R1c-EFLS/EFLE = Deletion2 due to a reduction1 of a clause with loss of communicative effectiveness and/or emphasis with respect to the original text.

21) D2-R1p-EFLS/EFLE = Deletion2 due to a reduction 1 of a phrase with loss of communicative effectiveness and/or emphasis with respect to the original text.

22) D2-R2c-EFLS/EFLE = Deletion2 due to a reduction2 of a clause with loss of communicative effectiveness and/or emphasis with respect to the original text.

23) D2-R2p-EFLS/EFLE= Deletion2 due to a reduction2 of a phrase with loss of communicative effectiveness and/or emphasis with respect to the original text.

\section{Sobre didáctica de la traducción}

\section{RÉSUMÉ}

Le grand nombre d'écrits sur la théorie et la pratique de la traduction n'est pas comparable à celui consacré à la didactique d'une activité dont l'étude et l'apprentissage font depuis longtemps l'objet de recherches universitaires.

Les raisons de ce déséquilibre sont nombreuses et variées, l'absence d'unanimité entre les spécialistes dans ce domaine, sur la nature et l'objet de la traduction, étant peut-être l'une des plus importantes.

Puisqu'il nous faut former des étudiants à la pratique de cette discipline, une méthodologie cohérente et rigoureuse, conçue à partir d'une théorie claire qu'il soit possible d'appliquer à la traduction de tout type de texte, s'avère nécessaire.

Cette méthodologie atteindra son but si nous parvenons à montrer aux étudiants un point de départ, des objectifs et un parcours intermédiaire, suivant des considérations traductologiques dont le dénominateur commun est leur vocation de faciliter la communication entre la culture de départ et la culture d'arrivée.

Dans cet article nous présenterons notre modèle didactique, fruit de notre expérience dans l'enseignement universitaire, mais qui ne prétend pas être exclusif. Ce modèle se veut seulement un point de départ pour la réflexion et une aide pour des professeurs et des étudiants.

\section{ABSTRACT}

There are many more works written on the theory and practice of translation than on the didactic approach to an activity whose study and learning have been the subject of university research for a long time.

The reasons for this imbalance are numerous and varied. The most important one is certainly the lack of unanimous consensus between specialists as to the nature and object of translation.

Since our job is to teach and train students to be translators, it is necessary to implement a coherent and rigorous method based on a clear theoretical approach that applies to all types of texts.

Such methodology will achieve its aim if we manage to show the students a starting point, some objectives and the process in-between, following some factors whose common denominator is their vocation of making communication easier between the source culture and the target culture.

In this article we shall show our didactic model, the fruit of several years' university teaching. However, it is not thought to be exclusive. It is simply the starting point for reflection and assistance for teachers and students alike.

\section{MOTS-CLÉS/KEYWORDS}

théorie, didactique, méthodologie, rigueur, communication

\section{Introducción}

Antoine Berman, en su prólogo a L'Épreuve de l'étranger, concluye que la estructuración de la historia de la traducción, de su ética y de su analítica son los tres ejes en los que debe apoyarse cualquier reflexión moderna en torno a la traducción. En la actualidad, algunas universidades españolas vienen celebrando 
congresos y jornadas, cuyo objetivo, precisamente, es profundizar en el primero de los aspectos mencionados ${ }^{1}$, preocupación que coincide, pues, con el punto de vista del traductólogo francés, que, desde luego, compartimos.

Una historia de la traducción, no obstante, especialmente en nuestros días, debería también integrar una historia de su didáctica pues, como es sabido, desde épocas muy remotas, muchos textos traducidos van acompañados de notas, sugerencias o meras reflexiones de sus traductores, que generalmente se limitan al texto concreto traducido. A este respecto, reproducimos aquí la cita del prólogo del Eclesiástico o Sirácida, en torno al 132 a. de C., que el Dr. Santoyo recoge en su magnífico ensayo, "Del scriptorium a la academia", en la que, por primera vez, un traductor "opina sobre su propio trabajo." Dice así:

Quedáis, pues, invitados a leer [este libro] con benevolencia y atención, mostrándoos indulgentes si, a pesar de nuestros esfuerzos por interpretarlo, no hemos logrado dar alguna vez la debida expresión a las palabras, pues las cosas dichas en hebreo no tienen la misma fuerza cuando se traducen a otra lengua. Esto ocurre no sólo en este libro, sino que en la misma Ley, los Profetas y los restantes libros se aprecian no pequeñas diferencias con respecto a lo que dice la lengua oriental (100-101).

Pero, a pesar de que ha llovido mucho desde que estas palabras fueron escritas y de que hace ya más de cincuenta años que la Universidad se encarga de formar a futuros traductores; a pesar de la abundante bibliografía sobre la traducción, todavía no contamos con suficientes análisis sistematizados sobre esta rama de los estudios traductológicos, la didáctica, pues, como el autor citado sigue diciendo en el mismo ensayo: "no hubo durante todo el Medioevo, ni en el Renacimiento, ni desde la Ilustración hasta el siglo XIX una sola institución docente que se dedicara a la formación de traductores," teniendo que aguardar hasta la mitad del siglo XX, para que aparezcan centros superiores, tales como el de Ginebra o el de la Sorbona, dedicados a la enseñanza de la traducción.

Este trabajo no es, ni pretende ser, un ensayo estructurado y profundo sobre la historia de la didáctica de la traducción, tema que, sin embargo, merece nuestra atención, sino una mera reflexión nacida de nuestra experiencia personal en esta rama de los estudios traductológicos, motivada muy especialmente por la necesidad diaria de procurar un camino de aprendizaje a futuros traductores; en nuestro caso, a alumnos de la Facultad de Traducción e Interpretación de la Universidad de Las Palmas de Gran Canaria (Islas Canarias, España) ${ }^{3}$. Por encima de las objeciones de practicantes y teóricos de la traducción, el pedagogo necesita perentoriamente "fabricarse" "une morale par provisión," un método, que le permita formar académicamente a sus alumnos en una disciplina, cuya característica primera es su interdisciplinaridad y su objetivo la comunicación. Necesita aunar teoría y práctica, como vectores convergentes a lo largo de todo el proceso de la traducción de un texto.

\section{Teoría y didáctica de la traducción}

El enfoque teórico del que arranque una didáctica de la traducción no debe caracterizarse por su rigidez pero, claro está, nuestra docencia tiene como receptores a unos alumnos que todavía no son traductores, aunque se pretende que lleguen a serlo, y es precisamente ese recorrido entre el pretender ser y el ser traductor, el que requiere un método, si no científico, sí preciso y riguroso, y como decíamos al comienzo de este trabajo, claro (añadiríamos que hasta "sensato"). Opinamos, pues, que en didáctica de la traducción deben establecerse unas pautas metodológicas rigurosas, claras y precisas, determinadas por las exigencias específicas del tipo de comunicación que es la traducción, aplicadas a cada tipo de texto.

Cualquier metodología, y, desde luego, una tan compleja como la de la disciplina de la traducción, dada la idiosincrasia del proceso traductivo, requiere, pues, como punto de partida unos principios teóricos coherentes acerca de la naturaleza de lo enseñado, y de los objetivos que se persiguen.

El motivo es que el futuro traductor necesita tener una idea correcta y clara de la esencia de aquello que va a aprender (a traducir), del objetivo que persigue a través de su aprendizaje (aprender a facilitar la comunicación intercultural), y de cómo avanzar en ese proceso (naturaleza de sus fases).

En didáctica, una línea teórica coherente perseguirá proveer a los alumnos de los útiles necesarios para adquirir dicha formación, mostrándoles un recorrido teórico-práctico, también coherente, que les permita conseguir su doble objetivo, en cada fase del proceso didáctico: la comprensión de un texto original, producido en otra cultura (TO) y posterior producción de su correspondiente texto meta (TM).

En primer lugar, creemos que una guía didáctica de la traducción debe apoyarse en las constantes de una línea teórica determinada. En este sentido, entendemos que la traducción (en este artículo siempre se tratará de traducción escrita) es un proceso eminentemente comunicativo, de esencia cognoscitiva, que encuentra su apoyatura material en el lenguaje. Como Rosa Rabadán, opinamos que el principio definitorio de la traducción es el de equivalencia comunicativa y funcional, según el cual todo TM, para poder 
ser considerado como tal, debe conservar hasta donde al traductor le sea posible, el sentido del TO, integrado por el conjunto de intenciones y objetivos de su autor, y que incluye las funciones para las que dicho texto ha sido creado por su autor, en una situación comunicativa dada ${ }^{4}$.

$\mathrm{Al}$ mismo tiempo, el texto meta resultante del proceso traductivo, debe ser aceptable para el lector de la cultura meta, lo que, entre otros aspectos, implica que un TM debe conservar las convenciones verbales y textuales, para cada tipo concreto de texto, de la cultura a la que va destinado. Así, un traductor español conocedor de la cultura francesa, y aunque el ejemplo es muy simple, al traducir al español y para un destinatario español una carta cuyo emisario es francés, no va a puntuar con una coma tras el saludo de introducción de la carta, sino con dos puntos:

Cher Monsieur,

Suite à......,

tomaría la forma:

Estimado Señor: Tras......

De todos es sabido, por otra parte, que la cultura francesa tiende más al empleo de algunos usos gramaticales que la española, como, por ejemplo, la voz pasiva, sin hablar de la mayor implicitud lógica de los textos franceses con respecto a los españoles. El traductor necesita, pues, conocer estos y otros muchos aspectos relacionados con las normas de comportamiento verbal de las culturas en contacto, para producir un TM que cumpla con el principio de aceptabilidad en la cultura meta ${ }^{5}$.

Así pues, respeto al programa conceptual del autor y aceptabilidad en la cultura meta son los dos pilares en los que se asienta nuestro concepto teórico de equivalencia comunicativa y funcional, entre un TO y su posible TM.

Algunos especialistas en la materia recomiendan una progresión en la enseñanza de la traducción, basada en la adquisición de determinadas destrezas, que más bien nos parecen de orden lingüístico ${ }^{6}$. Y sin poner en duda su eficacia en muchos otros ámbitos del saber, consideramos que la progresión pertinente en materia de traducción y de su enseñanza es la que tiene por objeto descubrir la naturaleza de lo comunicado en un texto, mediante un trabajo en el que, por supuesto, interviene el reconocimiento de los elementos lingüísticos que lo integran, contemplados siempre desde la óptica de su carga comunicativa, en una situación dada. Esta consideración didáctica excluye, por consiguiente, las denominadas "técnicas de traducción." Dichas "técnicas" pueden ser válidas para estudios contrastivocomparativistas a posteriori, pero su valor será eminentemente lingüístico o filológico. Esto no quiere decir, no obstante, que no sean pertinentes o no deban realizarse estudios comparativos de dos o más textos meta, desde un punto de vista de su grado de equivalencia comunicativa con respecto a un texto original, y del estudio de las respectivas convenciones verbales.

Pero en didáctica de la traducción, a nuestro entender, debe favorecerse especialmente una "técnica," la comunicativa, es decir, la encaminada a descubrir el sentido de un TO, dadas las intenciones y objetivos de su autor, tema, fuente de publicación, receptor y estructura funcional del texto, en una situación comunicativa concreta. Por esta razón, la progresión que se nos antoja más eficaz, a la hora de enseñar a traducir a los alumnos de nuestras facultades, obedecerá a dificultades temáticas y a las derivadas de las especificidades de cada tipo de texto. Junto a estas, se presentan también las lingüísticas, que preferimos incluir en la denominación de culturales, entendiendo que la lengua es una manifestación más de toda cultura. Esta circunstancia obliga al profesor a buscar textos, especialmente en los primeros cursos, cuyo nivel de lengua y tema sean asequibles y adecuados al grado de formación de cada grupo de alumnos.

Veamos el siguiente ejemplo:

Un jour, plus tard, quand la vague bleue aura fini de lécher même les murailles de Paris, il nous faudra raconter aux enfants des écoles et des électeurs, la prodigieuse aventure ascensionnelle de Jean-Pierre Raffarin. Cinq semaines en ballon. Du pur Jules Verne électoral! (extracto de un texto aparecido en LE MONDE, 10.06.02, bajo el título: L'Illustre inconnu)

No creemos que el objetivo principal del pedagogo, al encarar este texto, sea hacer ver a sus alumnos si, en su traducción deben "ampliar," "reducir," "comprimir" o "calcar." Cualquiera de esas "técnicas," e incluso otros procedimientos lingüísticos aún no sistematizados, se reflejarán en las explicaturas ${ }^{7}$ empleadas para permitir la comunicación entre este texto (su autor) y el receptor de otra cultura. Por lo tanto, lo que sí nos parece relevante para que "circule" dicha comunicación, es conducir a los alumnos al conocimiento de las alusiones implícitas y explícitas del texto en cuestión, así como a asegurarse que saben de quién se trata, en el caso de los dos nombres propios citados. Deberán informarse sobre el tema tratado, para obtener el exacto valor comunicativo de "la vague bleue" o de "cinq semaines en ballon," y su relación con "prodigieuse aventure ascensionnelle" y "electoral," por ejemplo.

Veamos una posible traducción (TM): 
Un día, dentro de algún tiempo, cuando la marea azul haya dejado por fin de minar las defensas de París, habrá que explicarles, a los niños de las escuelas y de los electores la prodigiosa aventura de la subida meteórica de Pierre Raffarin. ¡Una especie de cinco semanas en globo, al más puro estilo Verne electoral!

Conservar los marcadores de la intención del autor de este texto (especialmente, su tono irónicofestivo) y su información implícita, y dado que se trata de un texto idiolectal, esta podría ser una traducción aceptable del fragmento ofrecido. Para conseguir su equivalencia comunicativa con su correspondiente TO, carece de importancia traductológica si en el paso de este al TM el adjetivo "ascensionnelle" pasa a substantivo $\left(\right.$ subida $\left.^{8}\right)$, de mayor uso en la cultura de llegada, en una situación comunicativa como la del TO.

Íntimamente relacionado con un determinado enfoque teórico y con su interacción en el proceso didáctico de la traducción de un TO, está el hecho de contar con la elaboración y manejo de un glosario terminológico, que recoja las denominaciones principales de los conceptos u operaciones que intervienen en el acto de la traducción.

En algún lugar, recuerdo haber leído la opinión favorable al respecto del profesor Delisle, con el que coincidimos, por un doble motivo, de origen común. En primer lugar, los estudios traductológicos, para adquirir rigor y marchamo universitario, deben contar con una terminología propia, capaz de aplicarse y definir los diferentes aspectos y elementos constitutivos de la disciplina de la traducción. Por otro lado, la puesta en práctica habitual de una terminología propia especializada, que acompañe las distintas fases del proceso, ayudará a que los alumnos estimen la especialidad que estudian, al encontrar así una faceta más de su rigor académico?.

Creemos pues, que, en traducción, todo proyecto de proceso didáctico debe ir acompañado de un glosario que recoja la terminología empleada por el profesor, que se esforzará en que sus alumnos adquieran y empleen a su vez. Esta cuestión es tanto más importante y dicho glosario se hace tanto más necesario, cuanto que en traductología todavía se está muy lejos de haber alcanzado una unanimidad teminológica, que, por otro lado, quizá nunca se alcance, dada la idiosincrasia de las ciencias humanas.

\section{Tipos de textos y didáctica de la traducción}

Si la traducción es una actividad comunicativa, se entiende que cada texto es el resultado de un acto de comunicación, que activa la mayor o menor relevancia de uno u otro de sus participantes, así como la de los factores con ellos relacionados. A la hora, pues, de abordar teóricamente el proceso traductológico desde este enfoque, partimos de la aplicación específica del principio de equivalencia comunicativa a la especificidad de cada tipo de texto. Consideramos, por lo tanto, la existencia de una tipología textual cuya clasificación no coincide exactamente con la tradicionalmente contemplada por la lingüística, sino que más bien, es la resultante de integrar una serie de factores comunicativos, como función e intención, con otros convencionales, que, tanto lingüística como culturalmente, están al servicio de los anteriores. En este sentido parece ir el "foco contextual" de Hatim y Mason, noción que nos parece más completa y acertada que la basada únicamente en el factor función del texto, pues dos textos pueden tener la misma función principal y pertenecer a diferente tipología, como, por ejemplo, una noticia y un artículo científico.

Una primera clasificación textual metodológica podría incluir dos grandes bloques de textos: idiolectales y convencionales.

En los primeros, como se ha apuntado, predomina el uso idiosincrático de los elementos formales, al servicio de la subjetividad de un autor (artículos o comentarios de opinión, textos literarios o algunos ensayos). Por lo general, en este tipo de textos, las convenciones verbales, o normas de comportamiento verbal de una cultura, dejan paso a usos verbales, a menudo exclusivos de su creador, y los diferentes recursos lingüísticos se convierten en marcadores de su intención.

En el siguiente fragmento:

...Le train avance, je retrouve la pression d'autrefois que contrebalançait l'obscure, ou l'incisive interrogation de Miss Blanche..., ${ }^{10}$

la colocación idiolectal de la pausa introducida por la coma (el subrayado es nuestro) se constituye en marcador del proceso de reflexión del narrador, tal y como se va produciendo, a medida que la va plasmando sobre el papel.

En los textos convencionales, como su mismo nombre indica, predominan, por el contrario, las normas de comportamiento verbal que cada grupo social, como tal grupo, tiene establecidas para cada tipo de texto. Así, una carta comercial, según su objetivo y destinatario, tendrá un formato determinado; como también está "convenida" la estructura de una receta de cocina o la distribución textual de un acta de separación matrimonial o de compraventa de un inmueble. 
Esta u otras posibles clasificaciones de los textos, en modo alguno implica la total separación de sus elementos cconstitutivos. Puede decirse que, en todo texto, se mezcla lo idiolectal y lo convencional. A efectos metodológicos, sin embargo, clasificamos los textos, en función de su carácter más o menos marcado en uno u otro sentido, dependiendo de la mayor o menor presencia de elementos de una u otra índole. De este modo, y también a los mismos efectos, establecemos una subclasificación de textos mucho más variada, tanto dentro de los idiolectales (poéticos, novela, teatro, cuento, comentario de opinión, ensayo...) como de los convencionales. En estos, tal clasificación emana en parte de sus respectivos estilo y género funcionales que, a su vez, integran diferentes tipos y subtipos de textos (el estilo funcional científico, por ejemplo, aglutina desde el texto divulgativo hasta la ponencia de un premio Nobel ${ }^{11}$.

Nuestro enfoque didáctico de la traducción, sin embargo, entendido como didáctica de la traducción de distintos tipos de texto, no contempla la distinción entre texto especializado y texto "general," clasificación cuya filosofía quizá corra paralela a la tradicional entre textos literarios y especializados, que aplica esta última denominación solo a los textos relacionados exclusivamente con el área de conocimiento de las ciencias experimentales. Pero hoy, esta idea de especialización parece algo obsoleta, y se extiende a todo texto relacionado con cualquier ámbito del saber, incluidas las Ciencias Humanas, por lo que un texto sobre traducción se considera, por ejemplo, tan especializado como otro sobre medicina; lo que entre ambos variará, aparte del tema y de algunos otros factores, son sus condiciones de verdad y su grado de especialización, que origina una tipología en escala, desde los textos divulgativos hasta los más altamente especializados. La primera conclusión a la que nos conduce este planteamiento es que, en realidad, no existen "textos generales," pues todo texto pertenece a algún campo específico de la actividad humana. Esta consideración tiene también repercusiones muy concretas en el ámbito de la didáctica de la traducción, pues incide en la relevancia de uno u otro elemento del acto de comunicación que es un texto, determinando el proceso cognoscitivo del traductor.

Veamos, a modo indicativo y bastante incompleto, el siguiente cuadro de tipos de textos, y marcado con una $\mathrm{X}$ el elemento comunicativo relevante en cada uno de los grupos:

\begin{tabular}{|l|c|c|c|}
\hline TIPOS DE TEXTOS & $\begin{array}{c}\text { AUTOR } \\
\text { (PCA) }\end{array}$ & CONTENIDO & RECEPTOR \\
\hline $\begin{array}{l}\text { 1) Textos idiolectales (literarios, ensayos, } \\
\text { humanísticos, artículos de opinión...) }\end{array}$ & $\mathrm{X}$ & \\
\hline $\begin{array}{l}\text { 2) Textos legales y administrativos, } \\
\text { textos publicitarios,especializados. }\end{array}$ & & $\mathrm{X}$ & \\
\hline 3) Textos divulgativos, didácticos & & & $\mathrm{X}$ \\
\hline
\end{tabular}

Según nuestra perspectiva traductológica, el elemento comunicativo relevante en un texto idiolectal, por ejemplo, es el autor de dicho texto, subordinándose a él todos los demás participantes en el acto comunicativo. Esta es la razón de que la didáctica de la traducción de este tipo de textos, y muy especialmente de los literarios, trate de habilitar al futuro traductor, para que conserve en su TM el idiolecto ${ }^{12}$ del autor del TO, a pesar de que dicho idiolecto violente en algún aspecto las convenciones de la lengua de llegada, violencia que, en este tipo de textos, también se ejerce casi siempre sobre las convenciones verbales de la cultura de partida. Pensemos en el idiolecto de una Duras, por ejemplo. En alguna de sus novelas, encontramos réplicas enteras sin puntuar ${ }^{13}$, como marcador de las implicaturas textuales o sentido implícito del texto(angustia del emisor, por ejemplo). Este sentido implícito quedaría neutralizado si el traductor al español puntuara debidamente dichos párrafos, según las normas de la prosodia, en la cultura española ${ }^{14}$.

En el texto divulgativo, por el contrario, el autor pierde relevancia en favor de la relación tema/ receptor. Este, es absolutamente libre, en cuanto que su característica principal es carecer de características, ya que el texto divulgativo va dirigido a todo receptor que sepa leer y sienta curiosidad por ciertos temas. Esta circunstancia conlleva la pérdida del peso específico del autor del texto, que, por un lado, lo produce en función de la multivariedad de receptores (lenguaje estandar, terminología mínima, aumento de marcadores de las funciones apelativa y evaluativa...) y, por otro, no hace falta que sea especialista en el tema de su texto, sino simplemente "especializado" en el mismo ${ }^{15}$.

En los textos didácticos, la formula comunicativa, en teoría, podría ser la misma que para los anteriores, salvo que en los primeros, en los didácticos, el receptor está previsto, en razón de su edad, capacidad mental y, consecuentemente, grado de conocimientos. Por otra parte, el contenido de este tipo de textos debe ser aprendido, asimilado por el receptor al que, además, se pretende formar, no ya solo infor- 
mar. Retomando el término de Cormier, se trata, por tanto, de un receptor "captif" de sus propios condicionamientos físicos, mentales y conocimientos adquiridos. Esta circunstancia determina al autor de este tipo de textos, que, además de y más que ser conocedor del tema del texto, debe ser pedagogo, para saber transmitir su contenido en función de las características de su receptor.

En los textos jurídicos y administrativos en general, el elemento comunicativo relevante es su contenido, la ley, cuyo desconocimiento no exime de su cumplimiento, por parte del destinatario. En los publicitarios, lo relevante de la comunicación es el mensaje/producto, en realción con el receptor tipo al que aquel va destinado.

Dado que la finalidad y objetivos de sus autores producen tipos de textos diferentes, la teoría y la didáctica de su traducción deberán interesarse por todos los factores que intervienen en el proceso comunicativo textual, para dirigir la tarea cognoscitiva de los futuros traductores, en cada caso, a la hora de comprender un TO y de elaborar su correspondiente TM. La enseñanza de la traducción así considerada, debe partir de principios generales aplicables a todo tipo de textos, pues el proceso de preparación de un texto para su traducción requiere los mismos movimientos aunque diferentes competencias, tanto en el traductor profesional, como en los alumnos durante su período de aprendizaje. El ya citado A. Berman critica, en los siguientes términos, el enfoque de la escuela de Séleskovitch, según el cual, la traducción literaria y la técnica implican "el mismo proceso, el mismo principio con diferente aplicación"16:

Transposé au plan de l'écriture, cette affirmation revient à prétendre que la composition d'un poème et la rédaction d'une notice d'emploi obéissent aux mêmes principes et mettent en jeu les mêmes «processus cognitifs», pour reprendre une expression chère à cette école de pensée.

Y, sin embargo, creemos que, en este caso, el gran traductólogo se deja llevar por su especial consideración y reflexión sobre la traducción de textos humanísticos, que quiere ver como un proceso comunicativo aparte. Y lo es, pero, ante todo, también es comunicación, como lo es, por ejemplo, un folleto de instrucciones. Otra cosa es que los procesos cognitivos que conducen a la traducción de cada uno de estos tipos de textos apunten a competencias diferentes y de diferente signo, y que la naturaleza de lo comunicado sea también diferente. Así, el futuro traductor de un folleto de instrucciones para el manejo de un aparato, deberá conocer, hasta donde sea necesario, tanto el aparato al que se adjunta el folleto como su manejo y, claro está, las convenciones para este tipo de texto, en la cultura meta. En relación con el texto literario, serán otros los conocimientos necesarios, e irán encaminados, fundamentalmente, hacia el acercamiento e interpretación de la percepción y conocimiento del mundo del autor, elemento comunicativo relevante en ese tipo de textos. Pero, para la formulación y comprensión de uno y otro tipo de texto, los factores conocimiento y comunicación siempre serán imprescindibles e irremplazables.

Como hemos apuntado, lo que distingue a estos dos tipos de textos, desde un enfoque comunicativo es, esencialmente, la naturaleza de lo comunicado y cómo esta comunicación se lleva a cabo. Así, en los textos técnicos, el factor relevante es el propio mensaje dirigido a un público que necesita entender con claridad de qué manera debe proceder, para que el aparato que acaba de comprar funcione correctamente. $\mathrm{Y}$, con ese objetivo, debe formarse al futuro traductor, en la expresión de órdenes claras, exentas de ambigüedad, explícitas y precisas, conservando, como hemos dicho, las convenciones verbales de la cultura meta, para ese tipo de texto. En los textos literarios, por el contrario, y como decíamos antes, el autor del texto original, no comunica algo objetivo sino que se comunica a sí mismo, expone su propia percepción del mundo y experiencia de vida, creencias o ideas, generalmente de manera implícita. El futuro traductor necesita aprender el proceso de captación de todo aquello que no está explícito en este tipo de texto, sino implícito tras unos elementos lingüísticos, que el autor ha elegido como el medio más idóneo para transmitir ese mundo y percepciones suyas a los que nos acabamos de referir, de manera que, en este tipo de textos, lo no dicho en lo dicho y lo dicho implícitamente tienen un valor análogo.

\section{Lengua y didáctica de la traducción}

En cuanto al papel de la lengua en la traducción y en su didáctica, nuestro enfoque parte de una consideración instrumental de la misma, como utensilio necesario e importante para la comunicación verbal. Por esta razón, en nuestras clases, insistimos en la capacidad comunicativa de los elementos lingüísticos en un contexto dado. Este valor instrumental, por otra parte, va cargándose de sentido específico implícito, conforme un texto adquiere más valor idiolectal. Por excelencia, es en los textos literarios en los que lengua y sentido conforman las dos caras de una misma moneda, originando una unión excepcional entre fondo y forma, en razón de la cual, la alteración traductológicamente injustificada de la segunda puede conllevar la desnaturalización del primero y, consecuentemente, la desaparición de las señas de identidad o idiolecto, de su autor como veíamos antes, en el ejemplo de Duras. 
Pero ¿de qué es la lengua instrumento? Tal y como nosotros lo concebimos, de la expresión del sentido de un texto, de unas intenciones y objetivos, que se asientan en palabras. En resumidas cuentas, de la comunicación. Parece obvio decir algo así a estas alturas del desarrollo de los estudios traductológicos. La realidad, no obstante, aconseja insistir en la necesidad de recordar que, en esencia, la traducción no puede ser otra cosa que comunicación, aunque también haya significado, en determinados momentos históricos, la consolidación lingüística y cultural de un país, como pudo ocurrir en la Alemania de Lutero con su traducción de la Biblia, tal como Berman lo recoge en L'Épreuve de l'étranger. Así como para el Libro Sagrado, en el principio fue el verbo, para nosotros, en el principio de la traducción está la comunicación. Quizá sea esta cualidad uno de los factores que haya promovido el interés y proliferación de los diferentes enfoques traductológicos, pues uno de los misterios de la convivencia humana sigue residiendo en la dificultad del entendimiento entre los seres humanos. A menudo, oímos hablar de la imposibilidad de comunicarnos unos con otros, tanto en relación con las personas de nuestro entorno más íntimo, como entre pueblos de la misma o diferente cultura. En definitiva, la naturaleza de la comunicación es por definición subjetiva, y ahí radica su complejidad. Posiblemente, como decíamos, esta dificultad contribuya, junto con otras circunstancias, a los intentos tan variados por dar explicaciones, también muy variadas, acerca de lo que es la traducción.

En otro orden de cosas, al ser el texto el resultado materializado de un acto comunicativo, la unidad de comunicación será todo el texto, es decir, su sentido estará "repartido" entre todos y cada uno de los elementos que lo componen, tanto lingüísticos como extralingüísticos, de manera que el sentido de cada una de sus partes no podrá entrar en conflicto con las restantes, ni con el código hermenéutico de la totalidad de dicho texto. Descartamos así las "unidades de traducción," herederas de las denominadas "unidades de significado" de la lingüística, que proponen la enseñanza de la traducción, por fragmentos de textos, ya sean literarios o no.

\section{Conclusiones teóricas}

En el plano de la didáctica se hace, pues, necesario precisar previamente a los alumnos el enfoque teórico del que se parte, explicando, en definitiva, lo que el pedagogo entiende por traducción, e insistiendo en la relevancia de unos principios generales, entre los que podemos citar:

- el carácter interdisciplinar de la traducción

- el carácter comunicativo de todo el proceso de la traducción

- la reflexión sobre el tipo de texto, en cuanto resultado de una intención y de unos objetivos

- la necesidad de despejar las incógnitas culturales presentes en el TO

- la necesidad de recavar información sobre el tema aparente del TO

- la relevancia de uno otro de los integrantes del acto comunicativo, según el tipo de texto

- la información sobre las circunstancias de producción del TO

- la consulta de textos paralelos o de otros textos documentativos...

- el papel instrumental de la lengua en el proceso de la traducción de todo tipo de textos...

No es nuestra intención abundar aquí en estas consideraciones tipológicas que, en otras ocasiones ${ }^{17}$, nos han llevado a plantear la necesidad de formular una serie de teorías particulares de la traducción, encaminadas a completar y adaptar a cada tipo de texto, los principios generales de la traducción. Pero, de la misma manera y, consecuentemente con este enfoque, hemos llegado a la necesidad de establecer pautas didácticas, en íntima relación con la teoría de la que se parte, que pudieran desembocar en la formulación de una serie de didácticas particulares de la traducción, en función del tipo de texto objeto de la misma.

\section{Etapas del proceso de la didáctica de la traducción de un texto ${ }^{18}$}

Los principios teóricos citados, como se ha dicho, por encontrarlos comunes a la enseñanza de la traducción de todo tipo de texto, presiden el aprendizaje traductológico de nuestros alumnos. Nuestra experiencia nos viene demostrando la eficacia de la preparación en clase de la mayor parte del proceso de la traducción de un texto, especialmente para los cursos de primer ciclo ${ }^{19}$, exceptuando aquellas tareas que requieren el esfuerzo personal del alumno, como la búsqueda de la documentación pertinente o la confección del primer texto meta. Ambos pasos, no obstante, también son comentados y evaluados a posteriori, en el transcurso de las clases. Con la brevedad que impone el caso, vamos a revisar algunos pasos del proceso didáctico que llevamos a cabo, según el esquema del Anexo.

La primera etapa del proceso de la traducción de un TO, o "etapa preliminar," comienza, pues, con una fase teórica, a la que sigue otra de carácter eminentemente extratextual, integrada por una serie de 
deducciones traductológicas, propiciadas por los aspectos formales del TO. Resulta eficaz despertar las habilidades mentales de los alumnos, mediante preguntas encaminadas a que establezcan las primeras relaciones entre el objetivo que persiguen y la realidad textual, objeto de su estudio. Es decir, se trata de que los alumnos encuentren de antemano, por reflexión traductológica guiada por el profesor, muchas respuestas que van a serle de gran ayuda en su tarea traductora, mediante la observación del texto que van a traducir, y su ubicación tipológica.

Al entregársele a los alumnos un $\mathrm{TO}^{20}$, antes de proceder a su lectura, deben captar toda la información que aquel le suministra, a través de marcadores de diferente naturaleza: títulos, caracteres, marcadores semióticos ( imágenes, color...) presencia o no de columnas, autor explícito o ausente, fuente de publicación, tema explícito o implícito....Cuando se trata, por ejemplo, de un texto divulgativo, su formato, iconos, características del título y tema, que en origen pertenece a un campo específico y especializado del saber, así como el hecho de ir firmado frecuentemente, la fuente de publicación, y la abundancia de marcadores de sus funciones apelativa y evaluativa, son otros tantos marcadores del tipo de texto, luego de la intención de su autor, de sus objetivos y de su función. En este tipo de textos, de muy bajo grado de especialización, estas funciones llegan a igualar y hasta superar cuantitativamente, a los marcadores de la función informativa. Veamos el siguiente título de un texto divulgativo sobre astronomía, trabajado en clase y tomado de la revista divulgativa Sciences et vie:

\section{L'astronomie moderne l'a démythifiée, mais notre Galaxie reste un mystère}

Los elementos lingüísticos “démythifiée” y "mystère," son marcadores de la función apelativo-evaluativa, casi ausentes, por lo general, en un texto de mayor grado de especialización. Estos términos colaboran con "astronomie" y "Galaxie," identificadores del tema, en la localización tipológica del texto, pues dichos marcadores no se emplearían seguramente de igual manera, e incluso desaparecerían con esa forma, si el texto sobre Astronomía fuese de mayor grado de especialización, es decir, escrito por especialistas y dirigido a especialistas o futuros especialistas en el mismo ámbito del saber. En ese caso, este título se vería remplazado, por ejemplo, por algo como:

\section{Estructura y composición de nuestra galaxia}

Un texto puede también informar a priori a los alumnos bien preparados, acerca de algunas de sus dificultades de traducción, relacionadas con la mayor o menor divergencia de las convenciones verbales de las culturas en contacto. Además de esta información y de otras posibles, el tipo de texto orienta a los alumnos hacia el proceso cognitivo que tal texto requiere. Siguiendo con la tipología divulgativa, los alumnos, para la comprensión del TO y posterior producción del correspondiente TM, abren su investigación hacia la búsqueda de dos tipos de textos:

- $\quad$ sobre el tema del TO, que les proporcionen los conocimientos mínimos necesarios para comprenderlo, también mínimamente, y estar en situación de producir un posible TM, y

- "textos paralelos"21. En estos, los alumnos van a encontrar resueltas, en todo o en parte, los siguientes aspectos del texto:

- $\quad$ información sobre el tema

- $\quad$ terminología específica de ese campo de saber (deben elaborar y adjuntar a su dossier el correspondiente glosario)

- $\quad$ convenciones verbales y textuales de la cultura de llegada para ese tipo de texto, factor de gran ayuda durante la fase de producción del texto meta.

Nuestra experiencia nos viene demostrando que las fases de reflexión traductológica a la vista del TO y la de documentación sobre sus elementos comunicativos relevantes (autor, tema, receptor) resultan clave en el proceso de su traducción, habiendo comprobado que su cumplimiento exhaustivo, casi garantiza un TM comunicativamente equivalente al texto original.

La documentación sobre el TO es una fase que los alumnos realizan individualmente. Posteriormente, en la clase, se comentan los respectivos hallazgos, complementándose informativamente unos alumnos con otros. Para la comprensión del texto literario (relato o novela corta), Jour de marché à $D_{a n k i^{22}}$, los alumnos recurrieron a la Embajada del Senegal, que proporcionó datos determinantes para penetrar en la intención del autor del texto, como la existencia real de Danki y de los lugares que el texto cita, así como la generalización de dos nombres que aparecen en el TO, Diallo y Fatou, en principio nombres propios, pero utilizados ahora como genéricos de sirviente masculino y femenino, respectivamente. Estos datos, se unieron a la investigación sobre el propio autor del texto, para conocer sus ideales político-sociales, su literatura de compromiso, su propia nacionalidad y raza, etc., como marcadores extralingüísticos del sentido del texto. 
Otras fases de la etapa preliminar de la preparación de un TO para su traducción son:

- $\quad$ solución de incógnitas lingüísticas y, en su caso, terminológicas

- localización y solución de incógnitas culturales

- $\quad$ estudio idiolectal del TO (textos idiolectales)

Durante la primera de estas fases, se insiste en que los alumnos abandonen la tendencia, comprensible en cierto modo, a recurrir de inmediato al diccionario, que solo deben consultar cuando ya sepan el significado de la palabra desconocida, para buscar un sinónimo más adecuado. La etapa de comprensión semántica, con alumnos de primer ciclo, se lleva a cabo con todo el grupo, también durante la clase, procurando orientarlos al significado de la palabra desconocida, por el cotexto. La terminología debe resolverse fuera de clase, siguiendo las indicaciones de la profesora de la asignatura y las del profesor de Terminología.

El segundo punto reseñado supone el esclarecimiento por parte del alumno de aquellas alusiones a hechos, personas, lugares o cosas, que en principio, desconocen, y que detectan a lo largo de las sucesivas lecturas del TO. Recordamos, a este respecto, un texto de opinión firmado por Jacques Lang ${ }^{23}$ durante su primera etapa como ministro, en el que se aludía a personajes como Mazarino o Michel Serres, a los países que componen la francofonía y a la calle Valois, por citar algunas indicaciones que los alumnos desconocían en todo o en parte. Para la comprensión del sentido del texto, los alumnos necesitaron conocer estas realidades, así como el peso del autor, ministro en ejercicio, como se ha dicho, que lanza una encendida diatriba en contra de la xenofobia, dada también la relevancia de la situación políticosocial en Francia, en el momento de producción de este TO.

Una faceta importante del proceso didáctico de la traducción de un texto, especialmente cuando se trata de textos idiolectales, la constituye el estudio de su idiolecto, para que los alumnos reparen en la forma personal de expresar un autor su percepción individual del mundo. En el caso del relato al que antes nos hemos referido, por ejemplo, los siguientes son de sus rasgos idiolectales más sobresalientes, que los alumnos deben reconocer:

\section{Características léxicas}

- léxico sencillo, con algunos elementos propios de la cultura de producción del TO

- empleo de elementos muy descriptivos y evocadores, como jeune et plein de force, aussi léger qu'un oiseaux, voix soupçonneuse, regard chargé de mépris, maison nichée au fond d'un impasse, une triste mastication dans l'obscurité,....

- $\quad$ introduce elementos de un registro familiar, llegando pocas veces a niveles más coloquiales. Ejemplo de los primeros: avoir des histories, m'a détalé, assez quelconque, je laisse passer l'orage, de son baratin... Entre los segundos, situamos las expresiones: une vraie salope,celle-la o con la exclamación bordel!

\section{Características sintácticas}

- $\quad$ sintaxis correcta, en la línea clásica de expresión francesa.

- $\quad$ se alternan las frases cortas (generalmente cuando describe una situación de tensión) con otras más largas, aunque, por lo general, no superan las cuatro oraciones.

- el tono textual varía, entre lo casi jocoso a lo patético y más sostenido

La segunda etapa del proceso de la didáctica de la traducción se encamina a la comprensión semántica en sí, de un determinado TO, y a su vez se compone de tres fases. Durante la primera de ellas, los alumnos proceden a la búsqueda de la lógica del desarrollo del texto, mediante el resumen de cada uno de los enunciados y párrafos que lo componen, y la localización de sus relaciones de lógica semántica (causa efecto, condición, concesión, finalidad u otras). En la traducción del francés al español esta etapa adquiere gran pertinencia puesto que, en la cultura de partida, tales relaciones semánticas a menudo se implicitan tras un signo de puntuación, por lo general un punto, lo que dificulta la comprensión de los alumnos españoles, especialmente durante el primer ciclo. En la cultura de llegada, por el contrario, el uso suele favorecer el empleo de conectores que expliciten las relaciones semánticas existentes ${ }^{24}$.

Así, un texto de estructura habitual y correcta, producido en la cultura francesa podría ser el siguiente:

Aujourd'hui je ne sors pas. Il pleut.

La relación semántica de causa-efecto entre ambos enunciados se implicita tras el punto. Sin embargo, en la cultura española, el mismo texto explicitaría normalmente dicha relación mediante un conector causal:

Hoy no salgo porque llueves.

En la traducción y didáctica de la traducción de textos literarios, este aspecto adquiere especial relevancia, y exige dirigir a los alumnos al conocimiento de las convenciones verbales de las culturas en 
contacto, a fin de que sepan diferenciar en un TO lo que es idiolectal de lo que es convencional. Veamos los siguientes fragmentos de Un jour de marché à Danki:

A) Je ne savais pas qu'il avait problèmes de cœur. Je ne savais rien de lui. C'était de sa faute. Il n'avait jamais voulu me parler. Je lui ai planté le couteau partout. Je ne pense pas avoir fait cela exprès, je veux dire de tuer un type déjà en train de mourir. J'avais peut-être envie d'être un coupable (146)

B) C’est à cette seconde précise que j'ai eu envie de lui parler. Lui dire mon vrai nom. Qui je suis. Que je ne m'appelle pas Diallo et que j'ai roulé ma bosse partout. Que j'ai eu une riche vie, moi.

C'est à ce moment que j'ai pressenti la vérité.

L'homme ne m'avait pas vu.

Monsieur Soumaré ne m'avait jamais vu.

Ses yeux étaient ailleurs, très loin au-dessus de ma tête. Pour lui, je n'existais pas. Un objet dans la maison, moins précieux que ceux qu'ils ont dans leur beau salon (138).

En A), predomina una forma de expresión escrita, que lee el pensamiento del narrador, transcribiéndolo tal como lo comunicaría a otra persona, en alta voz. De ahí, «c'était de sa faute»o «être un coupable». Pero, estructuralmente, el fragmento se ajusta a las normas verbales de la cultura francesa. En estos casos, las relaciones de lógica semántica, implícitas convencionalmente tras un punto, pueden, y hasta quizá deban ser explicitadas en un TM al español, ajustándose a las convenciones de la cultura de llegada. De manera que el siguiente podría ser un posible TM de A):

No sabía que padecía del corazón, no sabía nade de él. Pero él tuvo la culpa, por no querer nunca hablar conmigo. Así que, le clavé el cuchillo por todas partes. De todas formas, no creo haberlo hecho a propósito. Me refiero a eso de a matar a un tipo que ya se estaba muriendo. Quizá lo que yo quería era convertirme en culpable.

El carácter idiolectal de B), sin embargo, es bastante mayor, dirigiendo las posibilidades del traductor más hacia la consecución de "l'esprit de l'œuvre," que dice Berman. Los alumnos aprenden a valorar y conservar en su TM los siguientes aspectos del TO:

- $\quad$ su estructura idiolectal textual, aunque esta no se ajuste a las convenciones verbales de la cultura española, como, por otra parte, tampoco se ajusta a las francesas

- $\quad$ sus marcadores prosódicos (ritmo)

- enfáticos (progresión de la intensidad emotiva del texto)

- lingüísticos

- de tonalidad...

Un posible TM de dicho fragmento sería:

Y en ese preciso instante, fue cuando sentí deseos de hablar con él. De decirle mi verdadero nombre. Quién soy. Que no me llamo Diallo y que me he pateado medio mundo. Que yo sé lo que es la buena vida.

Y en ese momento, fue cuando presentí la verdad.

El hombre no me había visto.

El señor Soumaré nunca me había visto.

Su mirada apuntaba en otra dirección, mucho más lejos, por encima de mi cabeza. Yo no existía para él. Había un objeto más en la casa, aunque menos valioso que los de su hermoso salón.

Tras el análisis semántico-lógico, debe dirigirse a los alumnos a la realización de un segundo análisis, ahora pragmático-funcional, encaminado a localizar en el texto aquellos elementos lingüísticos y extralingüísticos que se convierten en marcadores de la intención del autor del texto, así como de las funciones de éste. Como antes se avanzaba, en un texto divulgativo aparecerán numerosos marcadores de las funciones apelativa y evaluativa, además de los de la función informativa. En los primeros cursos, recomendamos a los alumnos marcar con colores diferentes los marcadores de las diferentes funciones, a fin de que se habitúen visualmente a identificar también los tipos de texto por su jerarquía funcional.

En un texto literario, la mayor parte de sus marcadores lo serán de la función emotivo-evaluativa; en un texto de alto grado de especialización, primará la función informativa; en un texto técnico, la operativa; en uno publicitario, la apelativa; en un texto divulgativo, como se ha dicho, las funciones informativa, evaluativa y apelativa pueden correr parejas en número de marcadores...

En cuanto a la primera parte de la etapa de producción del texto meta, la elaboran los alumnos individualmente, aunque posteriormente se lleva a cabo una puesta a punto común en clase. Digamos que elaboran un primer borrador que resultará tanto más aceptable cuanto más correctamente se hayan superado las etapas anteriores. En este momento, los alumnos deben tener en cuenta que van a servir de 
puente entre la cultura de partida y la de llegada, en la que van a introducir un texto que deberá responder a las expectativas verbales de dicha cultura de llegada, sin que su sentido deje de corresponderse con el del TO. Es, pues, necesario prestar gran atención al valor comunicativo y formal de los elementos lingüísticos elegidos en la cultura meta, a fin de conservar en el texto meta la tipología textual y los marcadores de las intenciones y funciones del original. A tal fin, se comenta en grupo el mayor número de variables posibles para cada caso, procurando que los alumnos descubran el grado de posibilidades comunicativas de cada una de dichas variables, dado el tipo de texto y factores relevantes de la comunicación. Nunca se ofrece una versión definitiva, sino que, tras esta puesta en común de posibilidades de traducción, cada alumno produce su texto definitivo, que añadirá al dossier que entregará a la profesora durante el examen final (en su caso). Resulta de gran utilidad analizar exhaustivamente las posibilidades comunicativas de los posibles elementos lingüísticos aplicables en cada caso, para que los futuros traductores aprendan a valorar las pérdidas y ganancias comunicativas en materia de traducción, y a decidir sus opciones en función de dichos valores comunicativos.

\section{Didáctica de la traducción y evaluación}

Lina Sader Feghali ${ }^{25}$ distingue tres tipos de evaluación: la de "pronóstico," la de "diagnóstico" y la de "inventario." El primer tipo viene a ser una especie de toma de contacto del profesor con su grupo de alumnos, por la que el primero se informa del nivel de conocimientos y grado de formación de los segundos. El segundo tipo supone, tanto por parte de los alumnos como del profesor, un medio de estar al tanto, a lo largo de todo el curso escolar, del progreso en la formación traductológica.

Por último, la evaluación inventario es un balance final, que el profesor establece, a la vista del trabajo y progreso de los alumnos, a lo largo de todo el período lectivo.

Nuestro enfoque didáctico asume prácticamente estos conceptos evaluativos. Nuestra experiencia docente nos viene demostrando que es contraproducente dejar en los alumnos la sensación de que se juegan su trabajo de un año en un examen final. Por otro lado, la naturaleza eminentemente teóricopráctica de los estudios traductológicos, requiere más que en el de otras disciplinas ( Historia o Literatura, por poner algún ejemplo) una evaluación continua, en la línea de la segunda opción de la especialista antes citada. El motivo que nos mueve a tal actuación pedagógica es procurar que los alumnos, a lo largo de todo el período de su formación y del proceso didáctico de la traducción de un texto, aprendan de sus logros y también de sus errores. Nuestra metodología evaluativa valora los siguientes aspectos:

- la elaboración individual del TM (tras los pertinentes análisis del TO correspondiente, en la forma anteriormente expuesta)

- entrega en la fecha convenida de un dossier compuesto por:

- copia del TO

- notas recogidas en las clases

- TM individual

- comentario traductológico del TM

- glosario del texto (en textos convencionales)

- ficha identificativo-descriptiva del TO

- documentos de apoyo (informativos y paralelos

- examen final (primer ciclo)

Tras la revisión de los dossier y de las traducciones (el profesor señala los errores de traducción pero no los corrige), se devuelven los trabajos a cada alumno. En clase, se lleva a cabo una corrección colectiva, procurando escuchar las dudas de todos los alumnos, a los que dirigimos hacia soluciones comunicativas, en relación estrecha con las coordenadas principales del acto de comunicación que es el texto.

Cuando un trabajo resulta no aprobado en primera instancia, los alumnos deben corregirlo, añadiendo dicha corrección a su dossier, que, en su caso, entregarán al profesor el día del examen final, junto con esta última prueba. Si un dossier resulta aprobado por curso, es decir, si no contiene ninguna traducción suspendida, los alumnos de segundo ciclo no están obligados a pasar un examen final, salvo que deseen subir nota.

En los cursos del primer ciclo, sin embargo, creemos que es conveniente pasar dicha prueba, aunque tengan aprobadas las traducciones del curso, a fin de que el profesor pueda evaluar con mayor precisión su capacidad de respuesta, ante las contingencias del lugar y del tiempo. En todos los casos, los alumnos pueden consultar el material del que dispongan, para su elaboración del TM de un TO, que eligen de entre los que el profesor les ofrece. En el primer ciclo, y en la asignatura Introducción a la Traducción Especializada, les ofrecemos un texto de cada tipología trabajada durante el curso. Junto con su traducción, el alumno debe entregar un comentario traductológico y un glosario, en el caso pertinente. 


\section{Conclusión}

Traducir supone comunicar, facilitar la comunicación. La traducción tiene, pues vocación comunicativa. Enseñar a traducir implica enseñar las dificultades y complejidades de tan peculiar proceso hacia su objetivo final, de manera que los futuros traductores sean conscientes de la importancia, dignidad y academicismo de la especialidad que han elegido.

Un enfoque comunicativo de la traducción debe estudiar y enseñar a distinguir los ingredientes inherentes a toda actividad humana, tales como subjetividad, intencionalidad u objetivos, en una situación comunicativa dada. La didáctica de la traducción deberá tener en cuenta estos factores y otros, que inciden los textos escritos, determinando su variedad tipológica, como resultantes de diferentes actos de comunicación, cuya complejidad invita a integrar con carácter preferente, en la multidisciplinaridad de los estudios traductológicos y en su didáctica, la filosofía del lenguaje y la teoría de la comunicación.

En nuestra opinión, enseñar a traducir implica, pues, proveerse de un método, cuyo punto de partida y objetivo final sea coherente con la naturaleza y objetivos de los estudios enseñados. Cualquier método empleado en didáctica de la traducción se nos antoja, posiblemente, mejor que la carencia de método alguno, y cualquier método empleado en didáctica de la traducción debería integrar teoría y práctica, a lo largo de todo el proceso didáctico.

Rosario García López Universidad de Las Palmas de Gran Canaria, Las Palmas de Gran Canaria, España rgarlo@eresmas.net

\section{NOTES}

1. La Universidad de León, concretamente, organiza regularmente un congreso internacional, cuyo título genérico es: Jornadas sobre Historia de la Traducción.

2. En Parallèles, n 19. El Dr. Julio César Santoyo es catedrático de la Universidad de León.

3. En España, contamos con algunos manuales de didáctica de la traducción, entre los que destacamos, por su orden de aparición, los de las Dras. Tricás, Hurtado, Lvovskaya (un capítulo) y Elena, cuyas señas bibliográficas completas recogemos en nuestras referencias bibliográficas.

4. Z. Lvovskaya, Problemas actuales de la traducción, Granada Lingüísitica: 1997 (La Dra. Lvovskaya es catedrática de Traducción e Interpretación de la Universidad de Las Palmas de Gran Canaria, Islas Canarias, España).

5. Como más tarde apuntamos, el peso de lo convencional en un texto va disminuyendo a medida que aumenta su grado de idiolectalidad. Una crónica, por ejemplo, presenta elementos idiolectales, relacionados especialmente con la evaluación que su autor hace del tema tratado. Sin embargo, dichos elementos idiolectales, tanto de forma como de fondo, aumentan cuando se trata de un texto literario, producto que, en su totalidad, emana de la subjetividad de su autor.

6. Vinay y Darbelnet señalan siete procedimientos técnicos de traducción (préstamo, calco, traducción literal, transposición, modulación, equivalencia y adaptación. La doctora Hurtado, en la obra reseñada, amplia dichas técnicas hasta diez y ocho (ampliación, amplificación, compensación, compresión, creación discursiva, descripción, equivalente acuñado, generalización, particularización, reducción, substitución y variación).

7. Sobre "implicaturas" y "explicaturas," remitimos a nuestro libro reseñado en la bibliografía.

8. Hemos añadido "meteórica," porque el sentido del texto, la intención de su autor creemos que lo admite y queda perfectamente clara para el lector de la cultura meta.

9. Es habitual escuchar a los alumnos preguntarse, refiriéndose a una traducción realizada: ¿Cómo te salióo Expresión que demuestra su concepto del trabajo que hacen, en el sentido de considerarlo como algo más bien producto del azar, que de un proceso lógico y riguroso.

10. Henry Bauchau (1966, ed. De 1998): La Déchirue. Bruselas, Labor (pag. 24)

11. Entre los estilos funcionales (periodístico, científico, administrativo, coloquial, legal) también nos parece que hay que contar con el estilo funcional publicitario.

12. Por "idiolecto" entendemos la unión íntima entre una percepción del mundo y la manera de expresar dicha percepción. Se aleja, pues, del concepto de "estilo," más relacionado con aspectos formales.

13. Ce qu'il faudrait c'est habiter une ville sans arbres les arbres crient lorsqu'il fait du vent ici il y en a toujours toujours à l'exception de deux jours par an à votre place voyez-vous je m'en irais d'ici je n'y resterais pas tous les oiseaux ou presque sont des oiseaux de mer qu'on trouve crevés après les orage et quand l'orage cesse que les arbres ne crient plus on les entend crier eux sur la plage comme des égorgés ça empêche les enfants de dormir non moi je m'en irais. Moderato cantabile, Les Éditions de Minuit, 1992 (pág. 79)

14. De hecho, la traducción de esta novela al español, de Rodolfo Alonso, restablece toda la puntuación, con lo que la intención implícita de su autora desaparece (Editorial Planeta, Barcelona; Compañía General Fabril Editora, S. A., Buenos Aires, 1961, edición de 1971)

15. Algunos periodistas, por ejemplo, se han especializado en temas de salud, medicina u otros, que publican en muchas revistas y espacios televisivos. Es el caso, en nuestro país, del periodista Sánchez Ocaña. 
16. «Traduction spécialisée et traduction littéraire», en La traduction littéraire, scientifique et technique, Paris, La Tilv. (9-15)

17. "El concepto de teoría particular, dentro de la teoría general de la traducción." VII Encuentros Complutenses en torno a la Traducción, Madrid, Editorial Complutense, 1999(pág. 121-131)

18. En el Anexo, ofrecemos unos modelos de esquema del proceso didáctico y de fichas, empleados en nuestras clases, y que recogemos en el manual de didáctica de textos idiolectales que estamos terminando, para ser publicado por los servicios de nuestra Universidad. Dicho esquema, puede adaptarse a todo tipo de textos. No pretendemos en modo alguno imponer nuestros croterios didácticos, sino exponerlos para ayuda de profesores noveles especialmente.

19. En nuestro país, la Licenciatura en Traducción e Interpretación consta de cuatro años académicos, divididos en dos ciclos: $1^{\circ}$ y $2^{\circ}$ cursos componen el primer ciclo, y $3^{\circ}$ y $4^{\circ}$, el segundo.

20. Para el primer ciclo, preferimos trabajar con textos de esencia divulgativa, técnicos, de grado medio de especialización, didácticos y publicitarios, cuya temática y relación con los alumnos no suponga dificultades demasiado específicas. En el segundo ciclo, los textos elegidos son mayor grado de especialización, y requieren en los alumnos una mayor formación traductológica y mayores conocimientos culturales. Pero, ya desde el comienzo de sus estudios sobre traducción, se inculca en los alumnos la conciencia de la multiplicidad tipológica de los textos y su diferente tratamiento.

21. Textos producido en la cultura meta, sobre el mismo tema, del mismo tipo y grado de especialización, y publicado en una fuente parecida a la del TO y dirigidos al mismo receptor.

22. Boucabar Boris Diop. Revista de Air France, 1998.

23. "S'enrichir, c'est se métisser», Fureur de lire, 1990.

24. Hablamos, claro está, de convenciones y tendencias de uso en cada cultura.

25. "Évaluation pédagogique de la recherche terminologique," Meta, XLVI,2, 2001, (pág. 426-437)

\section{REFERENCIAS BIBLIOGRÁFICAS}

Berman, A. (1984): L'Épreuve de l'étranger. París, Gallimard.

Cormier, M.C. (1990): “Traduction de textes de vulgarisation et de textes didactiques:Approche méthodologique», en Meta, XXXV, 4 (677-68

Elena García, P. (2001): El traductor y el texto. Barcelona, Ariel Lenguas Modernas.

García López, R. (2001): Cuestiones De traducción. Haica una teoría particular de la traducción de textos literarios. Granada, Editorial Comares.

Hurtado Albir, A. (1999): Enseñar a traducir. Madrid, Edelsa.

Lvovskaya, Z. (1997): Problemas actuales de la traducción. Granada, Granada Lingvistica.

RabadÁn, R. (1991) Equivalencia y traducción. Problemática de la equivalencia translémica inglés-español. Universidad de León, 1991.

Tricás Preckler, M. (1995): Manual de traducción francés-castellano. Barcelona, Gedisa.

\section{ANEXO}

Etapas del proceso didáctico de la traducción de un texto: esquema

1. ETAPA PRELIMINAR: FASES

- Fase teórica

- Presentación y reflexión sobre el TO

- Primera lectura: localización provisional del tema del TO

- Documentación

- Localización y solución de incógnitas lingüísticas

- Localización y solución de incógnitas culturales

- Estudio idiolectal del TO

\section{ETAPA DE LA COMPRENSIÓN DEL TO: FASES}

- Análisis semántico-lógico del TO

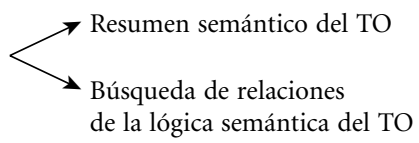

- Análisis pragmático-funcional del TO:

Búsqueda de los marcadores del sentido del TO

- Reformulación del tema del TO 


\section{ETAPA DE LA PRODUCCIÓN DEL TM}

- Fase preliminar de reflexión bidireccional:

Hacia el PCA

- Plan previo de traducción

- idiolecto y convención

- estudio de marcadores culturales

- búsqueda de equivalentes comunicativos en la CM

- primer borrador del TM

- Redacción definitiva de un posible TM

Ficha de trabajo del texto (para cumplimentar el alumno)

\section{TEXTO No:}

1. Título:

2. Autor:

3. Tipo de texto:

4. Fuente:

5. Fecha de publicación:

6. Argumento:

7. Tema provisional:

8. Bibliografía de partida:

9. Documentación:
$\square$ textos informativos
$\square$ reseñas
$\square$ textos paralelos
$\square$ internet?
$\square$ otros textos del mismo autor
$\square$ otros

10. Dificultades lingüísticas

11. Incógnitas culturales

12. Elementos convencionales del texto:

- predominantes:

- secundarios:

- sus características

13. Elementos idiolectales del texto:

- predominantes:

- secundarios

- rasgos dominantes

14. Jerarquía de las relaciones de lógica semántica

15. Jerarquía funcional del texto:
$\square$ apelativa
$\square$ fática?
$\square$ emotiva
$\square$ informativa?
$\square$ evaluativa
$\square$ operativa

16. Tema definitivo: 
Ficha de trabajo de texto literario (cumplimentar por el alumno)

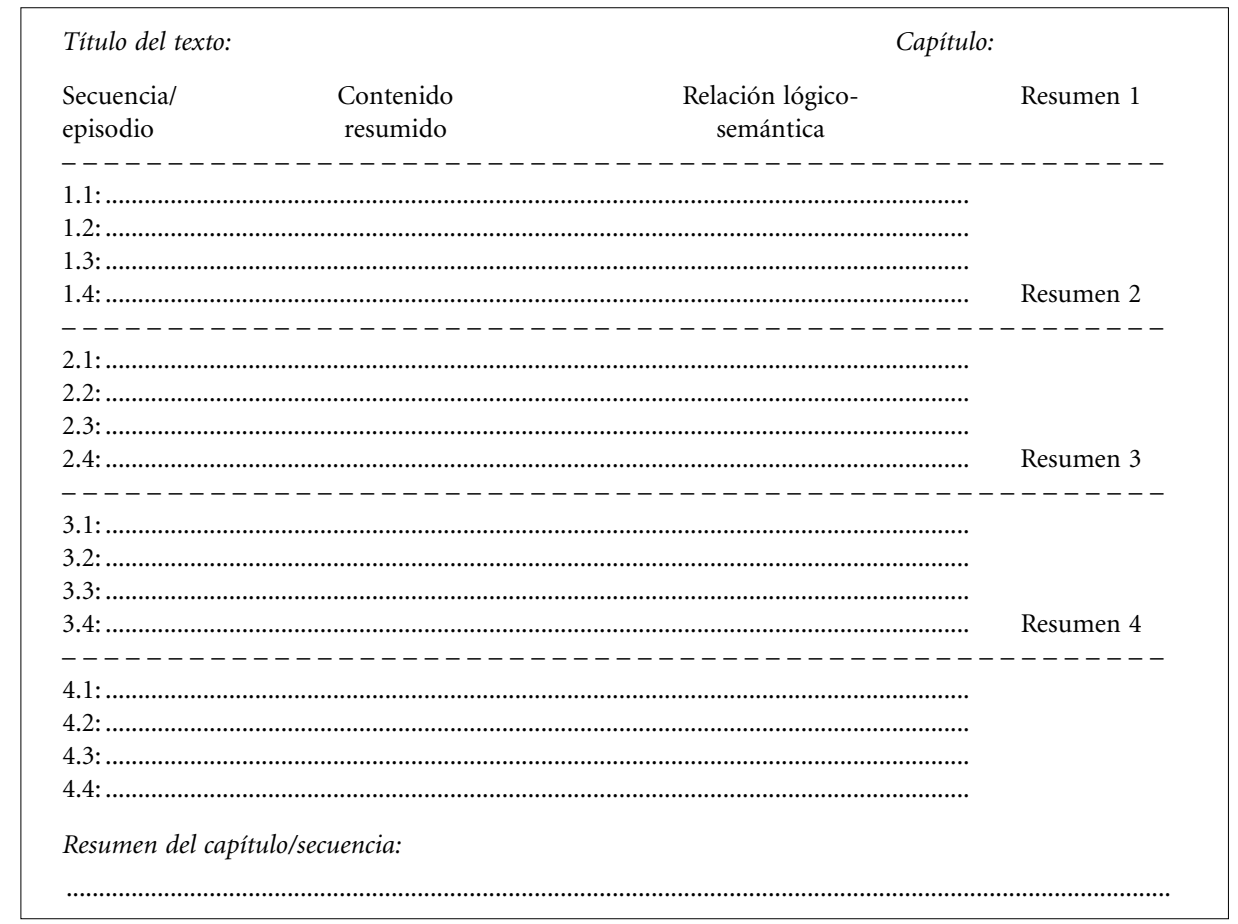

Ficha de evaluación de un texto literario (para entregar el profesor al alumno)

Título del TO:

NOTA

Argumento y tema aparente:

Código hermenéutico del TO:

Aceptable/No aceptable

Nivel de respeto idiolectal: Aceptable/No aceptable

$\square$ muy alto

$\square$ alto

$\square$ medio

$\square$ bajo

$\square$ muy bajo

Respeto de los marcadores del sentido del TO (de 0 a 10)

o prosódicos y fonéticos?

o léxicos?

o sintácticos?

o otros

o de la SC de producción

o de la SC de recepción

o de focalización

o semióticos

o tropos

Aceptación en la CM (de 0 a 10)

o adaptaciones culturales í

o convenciones verbales y textuales í

- ortografía

- sintaxis

- redacción

- puntuación

- otros

Conservación del código hermenéutico del TO: Alta/Media/Baja Comentario traductológico? 